\title{
Attitudes and Behaviours of Health Workers and the Use of HIV/AIDS Health Care Services
}

\author{
Jonathan M. Dapaah \\ Sociology and Social Work Department, Faculty of Social Sciences, \\ Kwame Nkrumah University of Science and Technology, Kumasi, Ghana \\ Correspondence should be addressed to Jonathan M. Dapaah; jmdapaah@hotmail.com
}

Received 5 April 2016; Revised 7 August 2016; Accepted 20 September 2016

Academic Editor: Kathleen Finlayson

Copyright (C) 2016 Jonathan M. Dapaah. This is an open access article distributed under the Creative Commons Attribution License, which permits unrestricted use, distribution, and reproduction in any medium, provided the original work is properly cited.

\begin{abstract}
Background. This article discusses how health workers relate to and communicate with clients of VCT and ART treatment. It also looks at how health worker practices in the form of attitudes and behaviours towards clients influence the use of these services. Methods. In-depth interviews, informal conversations, and participant observation were used to collect data from health workers providing VCT and ART and clients who access these services in two Ghanaian hospitals. Results. The study found that health workers providing these services, with the exception of a few, generally showed positive attitudes and behaviours towards clients during clinical encounters. Health workers warmly received clients to the facilities, addressing clients with courtesy, advising clients on a wide range of issues, sometimes supporting clients financially, and comfortably interacting with them. This is contrary to the findings of most studies in the literature that health workers often do not communicate and relate to these patients well. Conclusion. It concludes that dealing with clients well during interactions in the centres and clinics is crucial for reducing the perceived stigma associated with the use of services and increasing use as part of the national effort to reduce the infection rate of the disease in Ghana.
\end{abstract}

\section{Background}

The search for factors inhibiting people living with HIV and AIDS (PLWHAs) and others from voluntarily accessing counselling, testing, and treatment in Sub-Saharan African countries has brought into sharp focus how health workers interact and communicate with patients during provision of services. It is for this reason that this paper sought to look at how health care providers' practices towards PLWHA and others in the voluntary counselling and testing (VCT) centres and antiretroviral therapy (ART) treatment clinics influence the utilization of services in two Ghanaian hospitals.

In many Sub-Saharan African countries, including Ghana, there have been concerns about the way and manner some health workers relate to and communicate with patients in health facilities. Health workers, particularly nurses, sometimes do not treat patients or clients well. They may abuse patients; some nurses are rude and harsh towards patients and health workers often give immediate and high quality treatment to patients they know. For instance, Reis et al. [1] in a study in Nigeria found that a significant number of health professionals showed discriminatory attitudes and engaged in unethical behaviour towards patients with HIV/AIDS. This description is certainly the case as was also found by Jewkes et al. [2] in their study on nurses in South Africa. The authors indicated that some pregnant women expressed reservations of delivering in the hospital due to previous experiences of being shouted at, beaten or neglected by nurses. According to the study findings, although some nurses agreed with the reservations of the pregnant women, they attributed the practices to many factors. These were organizational issues, professional concerns, including perceptions that staff were themselves abused by patients, a perceived need to assert control over the environment and patients, social sanctioning of coercive strategies including punitive actions, and an underpinning ideology of patient ignorance and inferiority as further observed by Jewkes et al. [2] .

In another study, Andersen [3] pointed out that health workers in a Ghanaian hospital used education level to distance themselves from certain patient groups. In this regard, they distinguished between those patients who are entitled to high quality services and those who are not. Some patients, 
especially the uneducated, disparagingly called "villagers," were treated with impatience and discourtesy, given less information, and accorded less time. They were ordered around, yelled at, and accused of lying. It is for this reason among others that Larsson et al. [4] asserted that, when patients feel belittled verbally, a nurse may exercise the power of language or behave as a parent figure which negatively influences patient participation in nursing care. Zaroui et al. [5] further pointed out that improper attitudes of health personnel as people who are in touch with patients impose more pressure on patients. The authors contend such attitudes serve as a barrier for delivery of health services to HIVpositive patients. In Ghana today there is a widespread popular discourse that health workers are harsh and frequently treat patients without respect. Critical media reports about the poor quality of services provided in the country's health facilities can be found in press.

The instances cited above suggest that the image of health workers, especially nurses, in Ghana and some Sub-Saharan African countries is not good as reported in Böhmig [6]. Their practices are contrary to the popular and professional discourses that characterise nursing as a profession of dedicated staff, exhibiting qualities of care, nurturing, comfort, and concern and motivated by desires to help people that one sees in the United Kingdom according to Davis [7].

However, some studies have observed that most nurses reach professional ideals in their interactions with patients or clients during service provision. For instance a study in Mexico by Fusilier et al. [8] found that 81 per cent of health care providers interviewed were willing to provide AIDS care. It indicates that some nurses treat clients with attentive kindness and respect. Similarly, another study in Kentucky, United States of America, by Jaoko [9] noted that the majority of social workers (81\%) showed positive attitudes towards persons living with HIV/AIDS. Further, Marranzano et al. [10] observed in their study in Italy that although HIV was the nurses' main concern in regard to contacting infections in the workplace (54\%) the vast majority of them (98\%) never refused an HIV/AIDS patient care assignment. These practices suggest that there are health workers, especially nurses, who are patient and show respect towards clients while others are impatient and become irritated with clients who do not follow their treatment regimen.

The two hospitals in this study, whose names have been anonymized, were among the few health facilities in the Ashanti Region which benefited from the initial scale-up of VCT and ART in Ghana from 2004 to 2009. The region is the most heavily populated region of Ghana with 4,780,280 people representing 19.4 percent of the country's estimated population of 24,658,823 according to the results of the 2010 Population and Housing Census by Ghana Statistical Service [11]. The Ghana National AIDS Control Programme/Ghana Health Service [12] estimated that HIV prevalence for the Ashanti Region was 2.7 per cent in 2015. This figure is higher than the national prevalence rate of 1.37 per cent and is the second highest (after Greater Accra Region 3.2\%) out of the ten regions in Ghana. As at the end of 2013, there were 324 VCT centres and 26 ART clinics in the region according to the Regional Health Directorate.
It is worth noting that Ghana's HIV/AIDS epidemic has been characterised by a relatively higher HIV prevalence in urban areas compared to the rural areas. According to the HIV surveillance report of 2015, the mean prevalence of urban communities was 2.4 per cent and prevalence for rural communities was 1.4 per cent. The highest prevalence was also recorded within the age group 35-39 (3.45\%) and the lowest $(0.7 \%)$ was within $15-19$ age group according to the Ghana AIDS Control Programme/Ghana Health Service [12]. However, the fact still remains that Ghana's epidemic is one of the lowest in Sub-Saharan Africa which bears the greatest burden with more than two-thirds (69\%) of all persons infected with HIV. This relatively low infection rate in Ghana has been attributed to increased education about HIV/AIDS with the overall aim of reducing the impact and effect of HIV, while ensuring universal access to prevention, treatment, care, and support services. At the end of December, 2014, Ghana National AIDS Control Programme/Ghana Health Service [10] reported that there were 193 antiretroviral therapy sites and 2,152 prevention-of-mother to child transmission (PMCT) and HIV testing centres in Ghana.

The theory underpinning this article is agency. Thus, in spite of the persistent stigma associated with HIV/AIDS infection and the perceived unprofessional health worker practices towards clients, some health workers exercise agency by reaching out to clients through positive practices. The term agency here, according to Giddens [13] then, suggests intention or consciousness of action, sometimes with the implication of possible choices between different actions. It follows that most of the health workers in this study made the choice to consciously interact well and also politely communicate with clients in contrast to a few health workers who chose to show negative practices towards clients as would be seen later in the ethnographic data and the discussion presented below. To shed more light on how health workers interact and communicate with clients, I refer to the practices as "attitudes" and "behaviours." I use attitudes and behaviours as convenient terms to describe how health workers treat clients in their interactions during clinical encounters and not as theoretical concepts.

\section{Methods}

2.1. Study Population and Sampling Procedure. The study on which this article is based is part of a larger project made up of three interrelated studies on the provision and use of VCT and ART in Ghana. The anthropological study conducted an in-depth investigation of the social and cultural factors that discourage or inhibit HIV-positive persons and other people from using VCT and ART services largely from the supply (provider) side but also to some extent from the demand (patient/client) side. It was carried out in two health facilities providing voluntary counselling and testing (VCT) and antiretroviral (ARV) therapy and it examined how conditions in those institutions influenced use of these services. The hospitals were purposively selected for the study because they were among the few health facilities in the Ashanti Region which benefited from the initial scale-up of VCT and ART in Ghana as mentioned earlier above. The second 
project was conducted in the communities served by the above-mentioned hospitals. Social and cultural perceptions of blame, shame, and stigma took a central place in both researches. The third project considered the policy-making processes on international, national, and local levels.

Health workers were the primary target group and over 40 of them were involved in the study. Since it was not possible for all the health workers to be interviewed, twenty-four (24) of them were purposively selected for interview based on set criteria. The criteria included (i) the position of the health worker such as nurse-in-charge, pre and posttest counsellors in the VCT centres, and HIV/AIDS who interact with patients on a daily basis, (ii) at least two years working experience in the facility, and (iii) readiness to be interviewed. The researcher was of the view that a health worker who satisfied these basic requirements could effectively answer questions on the interview guide. Over 100 clients participated in the study as the secondary target group. Similarly, twenty-two (22) clients were also purposively selected for interview based on the following set criteria: (i) health condition of a HIVpositive person and (ii) the willingness to be interviewed. These requirements for clients were motivated by the fact that clients who looked very sick and traumatised by HIV-positive diagnosis will not be willing to talk about the challenges they were going through.

2.2. Methods of Data Collection. The data were collected through various qualitative research methods including participant observation, informal conversations, and in-depth interviews to collect data. These were supported with quantitative methods such as the analysis of hospital records and sociodemographic characteristics of clients. During the period of data collection, the researcher participated in daily activities in the centres and clinics and observed interactions between health workers and clients as study participants. More than forty health workers in the VCT centres and ART clinics were observed during data collection. The researcher also had informal conversations with health workers and clients to get their views on provision and use of services during participation and observation of activities in the clinics. A total of 24 health workers and 22 clients were interviewed. The health workers were made up of six nurses, five medical doctors, one pharmacist, one pharmacist technologist, two laboratory technicians, one disease control officer, five counsellors, one health assistant, and two cleaners. Seven clients who have been trained as peer educators to work in one of the clinics were also part of the study. The researcher was in the two hospitals for fifteen months to collect data. The first phase of data collection was twelve months, from July 2007 to June 2008. The second phase was three months, from November 2009 to January 2010.

2.3. Data Management and Analysis. Interviews were recorded and transcribed by the researcher. With regard to data collected through observation and informal conversation the researcher always had a memo book in a fieldwork bag in the facilities. During observation, participation, and conversation, I made a mental note of issues and actions that might be of interest to the study. I then intermittently withdraw to one of the staff rooms to write down what I had noted and later expand on them while at home. The transcribed interviews and the expanded notes from participation, observation and conversation were carefully read through and broken down into meaningful units and manually coded. The codes were grouped in broad categories that were defined and constructed on the basis of the data collected in line with Green and Thorogood's [14] ideas on coding and analysis of qualitative data. A summary was made for each category building on the common and recurrent responses as well as on different viewpoints. Various themes were identified based on the categories and illustrative quotations were also selected. Two broad themes were therefore identified, thus positive and negative attitudes and behaviours of health workers which influence clients' use of HIV/AIDS-related health care services as also observed by Dapaah and Senah [15].

2.4. Ethics. Ethical clearance for the research was sought from the Ethics Committees of Ghana Health Service, Ministry of Health, Ghana, and the two study hospitals. Consent of participation was received from health workers and clients of the VCT centres and ART clinics. Participation was voluntary and respondents could withdraw their participation in the course of the research. The study participants were also assured of anonymity in publication and all the names mentioned in this article are fictitious.

\section{Results}

3.1. Positive Attitudes and Behaviours. Much of the literature suggests that health workers in Sub-Saharan Africa, especially nurses, rarely show positive attitudes and behaviours towards clients who access HIV counselling, testing, and treatment services. In the few studies where health workers were reported to have shown positive attitudes towards clients, no mention was made of the specific type of attitudes or behaviours. Adebajo et al. [16], for instance, reported in their study that 90 per cent of care providers in Nigeria agreed to treat persons with HIV/AIDS. Also, Quach et al. [17] observed in their study that a third of physicians they interviewed had positive attitudes about providing care to HIV/AIDS patients. In essence, the good attitude these studies found was the willingness of care providers to treat positive persons. The present study also found that most health workers had good perception of clients and showed positive attitudes and behaviours towards them during interactions.

3.1.1. Warm Reception. It was observed in the centres and clinics that nurses often embraced or hugged clients who have not visited the clinics for a long time. Medical doctors and counsellors in the clinics and centres also welcomed clients with a smile and readily offered them a seat. They asked clients about their health before they were treated or counselling started. A client, Owusua, gave her impressions of the way a counsellor received her as follows:

Oh... He received me very well... Though the test showed that I do not have the disease, the way the counsellor nicely talked to me has encouraged me to come back in three months time for another test as he has requested. 
Health workers for their part explained that they gave a warm reception to clients who have strictly adhered to the treatment and survived the disease. Such clients have become role models for other clients who have persistently defaulted in their treatment regimen. They hugged these clients to motivate defaulters to adhere to treatment and feel appreciated by health workers. On the other hand a client who had defaulted treatment for about three months in a conversation pointed out that she received cold reception from two nurses (whom she described as her friends) the last time she visited the clinic. According to Araba, the client, the lukewarm attitude of the nurses towards her was an indication that they were disappointed in her for defaulting treatment for a long time and therefore she must take the treatment seriously.

3.1.2. Courtesy. Another way health workers behaved favourably towards clients was how they addressed them and communicated with them during consultations or conversations. Observations in the facilities showed that most of the health workers addressed clients politely. For instance, doctors, nurses, counsellors, and other staff addressed clients with traditionally accepted phrases and honorific titles such as "please" (mepa wo kyèw), "elder" (ópanyin), "madam" (maame), and "my friend" (madamfo) before they talked to them. The titles showed that these health workers respected clients irrespective of the disease they were suffering from.

Abrefi, a client observed as follows on the courteous behaviour of health workers towards her:

\section{I have observed that most of the health workers in this clinic treat clients well by showing cour- tesy towards them. For instance, this nurse [she mentions her name] is friendly and talks nicely to clients...}

This finding is in line with the observation made by Peprah [18] that respondents of a study in a Ghanaian hospital felt satisfied with service delivered whenever doctors and other health staff show courtesy towards them by talking politely to them during consultations.

3.1.3. Financial Support. Records in the centres and clinics with regard to the sociodemographic characteristics of clients showed that over 85 per cent of them were relatively poor. Most of these clients faced financial difficulties in making out-of-pocket payment for certain health care services not covered by the National Health Insurance Scheme (NHIS). The majority of them were unemployed and it was difficult for them to make a living. Some of the clients explained that they became unemployed after they got the infection. Others said that before they were diagnosed positive, they had taken their prolonged health problems to many places including hospitals, prayer camps, traditional healers, herbalists, and fetish priests for solution or cure. At each of these places, they spent huge sums of money to get treatment. Although they never succeeded, they continued spending large sums of their money at those places. A few of them pointed out that they lost their jobs because their employers thought they were spending too many working hours in hospitals accessing treatment. It was obvious that life was difficult for most of them to make a living.

It was in this dire financial difficulty most clients found themselves that some nurses in the clinics gave financial support to those who were relatively poor. The support from health workers to clients helped them to take transport back home after accessing treatment. For instance, Marie, a health assistant, used her own money on many occasions to buy food for clients who reported to the clinic in a weak condition because they did not have money to buy food.

3.1.4. Advice. Besides their official role as health care providers, some clients had taken health workers as their personal advisors on marital and family issues, as is made clear by Abrefi again in the following comment:

Because this muse (she mentions her name) is nice to patients, I always go to her with my treatment and personal problems for advice and she readily helps me... In fact we continue to access treatment in this clinic because most of the health workers here are kind to patients...

A male client called Bempa also recounted how he followed the advice of a nurse he had adopted as a mother and went for a bank loan to start a small business on his own. It is important to mention that through their advisory role, clients have adopted some health workers as their parents or relatives. They use them to take decisions about their treatment and other issues. This enables clients to exclude their actual family members from taking decisions in relation to their status and helped clients to hide their status from relatives as a coping strategy against stigmatisation associated with the disease.

3.1.5. Interacting Comfortably. On the whole health workers openly interacted with clients without hesitation. I eavesdropped on the conversation of two clients and one of them, Fosua, was of the view that the nurses in the clinic easily interacted with clients and added that the health workers are very friendly. Aba, the other client in the conversation, agreed and said that the health workers knew that one way they can encourage clients to continue accessing treatment is to be sociable with them.

Clients appreciated the good attitudes and behaviours of health workers towards them, which they said have encouraged them to continue accessing care and treatment. The next section describes the negative attitudes and behaviours of health workers.

3.2. Negative Attitudes and Behaviours. These are practices of health workers in the centres and clinics which were found to be contrary to the ideals of the health care profession. Some of these findings are in line with those reported in earlier studies, as will be seen in the ethnographic data presented below.

3.2.1. Poor Communication. It was observed in the centres and clinics that some health workers lacked the skills to communicate well with clients. Medical doctors and nurses 
in the clinics sometimes talked harshly to clients at the least provocation. They easily became angry with clients they considered to be troublesome or irritating and talked to or yelled at them angrily. This description fits with the observations made by Jewkes et al. [2] on the way nurses communicated with patients during the provision of obstetric services in South Africa. The authors cited an instance in which a midwife shouted at all the patients one day, complaining that they were careless about their health and that they would all have stillborn babies because they were stupid. This was how Manu, a client expressed concern about the way and manner a nurse talked to another client:

Some of the health workers do not know how to talk to patients with respect...They sometimes shout at clients like a nurse did to one client a moment ago for doing something wrong with his treatment. I saw that the man felt embarrassed because other clients were looking on. Probably, they sometimes talk to us [clients] this way because of the type of disease we are suffering from...

In the present study, a nurse became angry and shouted at a client to go out of her presence within hearing of other clients. There was also an instance in which a medical doctor made uncomplimentary remarks about a client by describing her as blockheaded and does not deserve to be put on ARV treatment.

3.2.2. Condemnation and Abuse. Clients who defaulted treatment or were considered irresponsible with regard to their treatment were often verbally abused or condemned by some care providers. For instance, in this study, Roseline, a nurse, openly said the following to a client she described as a persistent defaulter when he was brought to the clinic in a wheel chair while looking weak and lean:

You do not deserve any mercy from us for not taking your medicines once again. Clients like you should be left to die...

Health workers also in some instances condemned some clients as immoral people because they believed those clients caught the infection through commercial sex work.

Nurse Rebecca, however, explained that health workers do not take delight in abusing clients who default treatment. They often get frustrated with clients who do not adhere to treatment after all the effort put into three weeks of adherence counselling. So health workers sometimes expressed such disappointments in harsh words to compel them comply with treatment requirements. Comparing what happened in the present study with the literature brings out certain parallels. Brown [19], for instance, found in a study in the labour ward of a Kenyan hospital that midwives used physical abuse and restraint such as tying noncompliant patients to their beds so they would be still for examination during labour and deliver their babies safely. The parallels in this study and that of Brown [19] relate to how condemnation, scolding, and verbal or physical abuse were applied on clients and patients by nurses to improve compliance.
3.2.3. Controlling Clients. The health worker-client relationships in the facilities were ordered in a hierarchy of authority based on level of knowledge and technical competence. Andersen [3] points out that by their monopoly of medical knowledge, health workers have competence while patients by definition are incompetent because they need intervention of professional health workers to cure their ailments. Consequently, health workers have control over decisions and actions of clients in respect of their care and treatment.

In the clinics, clients who refused to take the orders or instructions of health workers were labelled uncooperative or irresponsible. Such clients were sometimes sanctioned or punished by health workers for objecting to their professional instructions or advice. Elsewhere, this type of client is referred to as "bad patient," "troublesome patient," or "disobedient" in Andersen's [3] terms. Andersen [3] further noted that the bad patient is the one who does not accept staff authority, recognise their monopoly on medical knowledge, or take their advice.

In one instance, a client challenged the decision of a nurse to first attend to another client who reported late to the clinic before attending to him. The nurse therefore refused to attend to the client when it was his turn in the queue because he challenged her authority. Likewise, Jewkes et al. [2] found that in the face of perceived insubordination, some midwives used punishment as strategy to enhance or enforce control during delivery.

3.2.4. Discriminatory Treatment. Health workers in the clinics often allowed elderly clients and others who were very sick and weak to get immediate treatment without joining long queues. They explained that this practice was due to the specific circumstances of such clients. It was however against hospital rules which stipulate that patients must wait for their turn to see a health worker. The rule was informally referred to as first-come-first- serve by both health workers and clients. During interactions and interviews with clients, they said that under the guise of helping such clients, health workers rather gave immediate treatment to their favourites and friends who reported late to the clinic. Boamah, a client stated in an interview that sometimes health workers ignored clients in the queues and provided immediate treatment to their friends and other people whose relatives are also health workers in the hospital. Another client also pointed out that care providers sometimes give preferential treatment to patients who are top government workers or businessmen and traditional leaders. According the client, health workers do not allow such people to join long queues and they are attended to immediately they arrive at the clinic for treatment.

Andersen [3] described this as differential treatment. She observed that, in a Ghanaian hospital, patients who are educated received immediate and high quality treatment in the hospital. The uneducated patients on the other hand often waited in long queues before receiving treatment. The friends or favourites of health workers in this study could be considered as the "educated" in Andersen's [3] study. As a result, they were given discriminatory treatment, especially in the clinics. 
These unprofessional practices have in many cases discouraged clients and potential clients from using counselling, testing, and treatment services.

\section{Discussion}

The positive attitudes and behaviours described in this paper raise the question of whether the practices of health workers in other units of the hospitals are as patient-friendly as those in the centres and clinics. An example in this respect was the financial support nurses gave to some clients. The positive attitudes and behaviours as reported in this study are striking against the backdrop of the assertion by Van Der Geest and Sarkodie [20] that, in Ghana, people generally feel nurses in hospitals are often unfriendly and rude, as previously indicated. Experience showed that nurses in the antenatal clinics, for instance, do not normally give mothers who accessed services money to take transport or buy food. However, it is not uncommon in Ghanaian hospitals to find a few nurses who behave positively towards patients like those in this study. Such practices could be based on compassion, which according to Russell [21] is the moral foundation of helping relationship between nurse and patient. This suggests that compassion in nursing practice strongly influences the nurse-patient relationship through which a nurse may support a patient or client in an unusual way. In their study, Van Der Geest and Sarkodie [20] found that nurses in a Ghanaian hospital ward sometimes spent their own money to buy food or drugs for patients. Similarly, Armstrong [22] reported in a study on demand-side factors affecting health seeking behaviour in Ghana that majority of the respondents continue to access services in certain hospitals because health workers treat them "very well." Others also described the treatment they received from the health workers as "kind" or "good." Compassion, which may have motivated these nurses or health workers to do this, could also be the reason for the financial support some health workers gave to clients in this study. The difference between health workers in the centres and clinics and those in other units may be how far they are prepared to go.

It was obvious that unlike their colleagues in other units, health workers in this study went beyond duty in their care for clients. For instance, warmly receiving clients with a hug was not common among health workers in other departments of the hospitals. Likewise, the advisory role of health workers in the clinics in relation to treatment and marital and family issues was a behaviour their colleagues in other units rarely showed towards patients. In other units, health workers usually advised clients on matters related to care and treatment, but not marital or family problems. These instances illustrate that care providers in the centres and clinics made a conscious effort to treat clients well during interactions to encourage them to continue using services.

The conscious effort of health workers to behave favourably towards clients suggests that their attitudes and behaviours were meant to create the impression that they related to and treated clients well. According to Turner and Stets [23], social actors' behaviour is self-directed. This implies that social actors sometimes adjust their behaviour to make things work in certain situations, achieve an objective, or even win the gratitude of others. Similarly, it could be that the good attitudes and behaviours of health workers were not genuine but "self-directed," to convince the researcher or visitors to the facilities that they were friendly and nice to clients contrary to the negative feeling Ghanaians have about nurses. To a certain extent, this view could be true, but the situation as was observed in the centres and clinics showed that the good practices of health workers were mostly real and not acted to please the researcher. Some of the positive attitudes and behaviours clients talked about happened before this study was carried out and there was no reason for them to describe these to please the researcher.

Besides, clients spontaneously talked about some of the favourable and unfavourable practices of care providers during informal conversations with the researcher. What is more, the researcher observed most of the attitudes and behaviours during fifteen months of fieldwork in the centres and clinics. Over this period, the researcher had a continuous presence in the facilities to observe the daily interactions between health workers and clients and participated in some of those interactions. It is obvious that health workers in the centres and clinics could not have continuously acted these positive attitudes and behaviours for a period of fifteen months without exposing themselves if they were not used to them.

Various reasons account for the positive attitudes and behaviours of health workers in this study. It is worth noting that HIV/AIDS prevention and treatment is a relatively new service area in the health care delivery system of Ghana. This made it necessary for health workers directly providing HIV/AIDS-related health care services to be given additional training in counselling, testing and treatment. The training, which is regular, has equipped them with the requisite skills to relate to and treat clients in a professional way compared to other health workers who have not received such training. Besides, it has helped these care providers to understand better the level of risks associated with caring for HIVpositive persons and also how to handle such risks. The special training has led to a greater willingness by these health workers to care for positive persons with less negative attitudes and behaviours towards them. Other studies also found that HIV training equips health workers to behave well towards clients during service provision. For instance, a USAID [24] study on health care providers in Tanzania observed that providers with HIV training had significantly higher knowledge scores than those without it, a result that is consistent with the possibility that HIV training can significantly improve such knowledge regarding HIV transmission and prevention. The study further noted that AIDS education among health workers, particularly nurses, led to significant improvement in attitudes towards patients (see also Horizons Program [25]). In the present study, it is obvious that the training and the refresher courses the health workers attend have contributed to the good perception they had about positive persons and their subsequent good treatment of them during interactions.

The friendly attitude and behaviour were also due to the life-long nature of the ART treatment. The fact is that when 
a client starts the treatment, he will continue to access the services until his death. It implies that the client will visit the clinic frequently for reassessment of his health status and resupply of antiretroviral drugs for the rest of his life. Having realised that the clients will need their care and treatment indefinitely, health workers deemed it appropriate to establish a longer-lasting relationship with them. Unlike other patients who visited the hospitals when they were sick, positive persons would keep on visiting the clinics, at least every month, three months, or six months for many years. If care providers treat clients with distaste, they may feel uncomfortable interacting with them during their visits to the clinics to access treatment. To avoid this situation, they behave nicely and in a friendly manner towards clients to establish good relationships with them and help keep them on treatment.

Clients for their part expressed satisfaction with the positive attitudes and behaviours of health workers towards them contrary to the stereotyping of nurses. It follows that clients developed good relationships with some health workers and individual nurses were selected for praise and often were spoken warmly about by clients. The relationship clients established with health workers helped them to adopt some care providers as their parents or siblings and consulted them for advice on a wide range of issues as noted earlier. This way, the positive behaviour of health workers encouraged the use of services, helping clients to avoid identification as positive persons by relatives and prevent stigmatisation.

Health workers have observed that clients find it difficult to discuss issues about their status with relatives due to the fear of stigma. In Ghana, positive persons are sometimes rejected, ostracised, or discriminated against by relatives for suffering from HIV/AIDS as observed by Crentsil [26] and Radstake [27]. Clients in those cases could not disclose their status to relatives and let alone enlist their help in managing the disease. This is contrary to the normal practice that patient's relatives fulfil their responsibility to help the patient find a diagnosis and treatment. When someone is sick, it is the family members who normally take decisions on care and treatment on behalf of the sick person. The patient who is deemed incapable of taking such decisions on his own depends on relatives for treatment and other necessary support. This implies that relatives have to know what type of sickness the patient is suffering from to enable them to look for appropriate treatment, either in biomedicine or the folk system. It is these people in charge of the decisionmaking process for the patient that Janzen [28] refers to as the therapy management group. He points out that the therapy management group is often made up of close relatives of a patient and in some cases neighbours or friends. In his study on social networks in times of illness in Abidjan, Bossart [29] points out that sometimes such close relatives also contribute financially towards cost of treatment for the patient. The group's responsibility goes beyond the popular and folk medicine and extends to the hospital setting. It is for this reason that Gruskin et al. [30] report that in many Sub-Saharan African countries, family members often accompany patients to health care settings to assist with certain aspects of patient care in case of hospital admission.
Ward environments and clinics tend to be characterised by overcrowding and lack of space for private discussions (see also Mulemi [31]).

Health workers have realised that this traditional form of shared care is not suitable for PLWHAs who do not want their status to be known. They therefore found it necessary to do something more than the routine provision of services to encourage clients to seek their advice on matters relating to their status. This enabled clients to forego their relatives as members of their therapy management group. It motivated health workers to get closer to clients and become quasi-members of their therapy management group. Clients adopted nurses as their mothers or sisters to replace their biological mothers and sisters. They managed the fear of stigma by choosing health workers as their therapy managers and conveniently used them to take crucial decisions related to their positive status, especially treatment.

Notwithstanding the explanations given for the positive attitudes and behaviours of health workers towards clients, the complex nature of health worker attitudes and behaviours would not be effectively dealt with if the drives for negative practices are not looked at. HIV/AIDS infection has over the years been considered as contagious, severe, and presumably the result of violational behaviour considered by many to be norm-violating such as commercial sex, homosexuality, and promiscuity as observed by Lyimo et al. [32]. This has led to the perception that the disease borders on morality in Ghana and its patients often suffer moral judgement, and it continued to be stigmatised as a "moral disease," according to Campbell et al. [33] by members of the general public as well as some health workers.

In view of this, it can be said that the unprofessional attitudes and behaviours of health workers in the present study were largely driven by moral judgement of clients. It follows that some clients who challenged the authority of health workers in this study were labelled as uncooperative or difficult thereby incurring the displeasure of health workers. Such patients were either spoken to in harsh language or were threatened with denial of treatment which suggests that they do not have the moral right to challenge the authority of health workers. Similarly, Hill [34] observes that patients who fail to validate clinician's sense of themselves as effective professionals, who threaten their control, and/or who create fruitless work are all subject to being labelled "bad patients." This label attracted negative attitudes or behaviours of health worker towards patients as also seen in the present study.

Furthermore, organizational norms could also influence health workers' moral judgement thereby influencing the way and manner they interact with patients. In this study there were instances in which due to burn out from heavy work load health workers were found treating clients with distaste. This observation finds meaning in a study finding by Varcoe et al. [35] which explained at length the contextual dynamics of labelling and its effects on relationship between health workers and patients. According to them, stereotypical thinking, moral judgements, and coercive behaviour increased in the context of time pressure and limited resources whether actual or perceived. 
It is also worth noting that negative health worker attitudes and behaviours in this study could be due to the fact that many participants framed HIV as immoral with the connotations of dirty and, therefore, do not deserve the sympathy of health workers. Thus the perceived saintliness of some health workers could have negatively influenced their interactions with clients because they consider HIV/AIDS as an immoral disease. Likewise, Shaw [36] reports that patients with mental illness, for instance, frequently represent dirty work for primary care physicians whereas moral or societal judgements may not matter when the same patients present with remediable problems. In this regard, HIV/AIDS can also be seen as dirty work for some health workers in this study since the disease, like mental illness, is often characterised with persistent stigma and the perception that HIV/AIDS is incurable or not remediable. Therefore, it is not surprising that some health workers chose to behave negatively towards clients as explained earlier.

The distasteful attitudes and behaviours of health workers towards the patients in the present study could also be explained from the generally held perception among many Ghanaians that HIV/AIDS is an incurable disease and patients are bound to die of the infection no matter the efforts put in by carers either in hospital or at home. This view resonates Duh's [37] observation that in Ghana stigmatisation of HIV patients is based on many factors including the position that there is no cure for the disease and its patients are going to die anyway and unfounded fears about HIV/AIDS. It is therefore possible that health workers like other members of the general public also hold similar perceptions of HIV-positive persons and the subsequent unfavourable attitudes and behaviours shown to them by care providers in this study.

Finally, reciprocity of liking in the hospital setting can influence the attitudes and behaviour. For instance, a study by Hall et al. [38] found that physicians liked their healthier patients more than their sick patients and healthier patients liked their physicians more. In this regard, it could be possible that health workers who attended to clients in this study did not to like some HIV patients or treated them unfavourably because they were looking very sick, especially those who were suffering from many opportunistic infections. In cases of this nature, health workers could treat patients with disdain because the perception is that after all they would not survive the disease.

\section{Conclusion}

In conclusion, there is enough reason to suppose that the way and manner health workers in the centres and clinics related to and behaved towards clients, particularly PLWHAs, was unusual in most Ghanaian health facilities. Unlike in other units of the hospitals, these health workers often went out of their way to help clients and to encourage them to continue accessing counselling, testing, and treatment. In other words, this category of clients were given "special treatment" in the facilities during service provision in view of the persistent stigma associated with the disease and the need to do everything possible to motivate them and other people to take up these services. This article establishes that the good practices of health workers in the facilities positively influenced the use of services and they stood in contrast to the often-reported negative practices in earlier studies. It further shows that if the environment and means by which health workers provide VCT and ART, as well as their perception and approach towards clients, are positive more people will be motivated to use services as part of the national effort to reduce the spread of the HIV/AIDS.

\section{Competing Interests}

The author declares that he has no competing interests.

\section{Authors' Contributions}

Jonathan M. Dapaah was the researcher and the sole author of the manuscript.

\section{Acknowledgments}

The author would like to express his gratitude to the Netherlands Organization for Scientific Research, NOW-WOTRO, which funded the entire research programme. The author thanks all the health workers and clients of the VCT centres and ART clinics of the hospitals which participated in the study for the patients with which they answered the many questions he asked. The author further acknowledges the contribution of his Ph.D. supervisor Sjaak van der Geest and two other colleagues, Dr. Rachel Spronk (a post-doctoral student) and Dr. Benjamin K. Kwansa, on the research programme towards the completion of this paper.

\section{References}

[1] C. Reis, M. Heisler, L. L. Amowitz et al., "Discriminatory attitudes and practices by health workers toward patients with HIV/AIDS in Nigeria," PLoS Medicine, vol. 2, no. 8, pp. 743-752, 2005.

[2] R. Jewkes, N. Abrahams, and Z. Mvo, "Why do nurses abuse patients? Reflections from South African obstetric services," Social Science and Medicine, vol. 47, no. 11, pp. 1781-1795, 1998.

[3] H. M. Andersen, “Villagers': differential treatment in a Ghanaian hospital," Social Science and Medicine, vol. 59, no. 10, pp. 2003-2012, 2004.

[4] I. E. Larsson, M. J. M. Sahlsten, K. Segesten, and K. A. E. Plos, "Patients' perceptions of nurses' behaviour that influence patient participation in nursing care: a critical incident Study," Nursing Research and Practice, vol. 2011, Article ID 534060, 8 pages, 2011.

[5] N. Zaroui, H. Joulei, E. Dorabi, and M. Faraouei, "Stigmatize attitude of healthcare providers: a barrier for delivery of health services to HIV positive patients," International Journal of Community Based Nursing and Midwifery, vol. 3, no. 4, pp. 292300, 2015.

[6] C. Böhmig, Ghanaian nurses at a crossroads: managing expectations on a medical ward [Ph.D. dissertation], University of Amsterdam, Leiden, The Netherlands, African Studies Centre, 2010.

[7] C. Davis, Gender and the Professional Predicament in Nursing, Routledge, London, UK, 1994. 
[8] M. Fusilier, M. R. Manning, A. J. S. Villar, and D. T. Rodriguez, "AIDS knowledge and attitudes of health-care workers in Mexico," Journal of Social Psychology, vol. 138, no. 2, pp. 203210, 1998 .

[9] J. Jaoko, "Social workers' attitudes towards people living with HIV/AIDS in Kentucky," Journal of Sociological Research, vol. 5, no. 2, pp. 56-62, 2014.

[10] M. Marranzano, R. Ragusa, M. Platania, G. Faro, and M. A. Coniglio, "Knowledge, attitudes and practices towards patients with HIV/AIDS in staff nurses in one university hospital in Sicily," Epidemiology Biostatistics and Public Health, vol. 10, no. 1, 2013.

[11] Ghana Statistical Service, Ghana National Population Census Provisional Report, Ghana Statistical Service, Accra, Ghana, 2010.

[12] National AIDS Control Programme/Ghana Health Service, HIV Sentinel Survey Report, National AIDS Control Programme/Ghana Health Service, Accra, Ghana, 2015.

[13] A. Giddens, The Constitution of Society: Outline of Theory of Structuration, University of California Press, Berkeley, Calif, USA, 1984.

[14] J. Green and N. Thorogood, Qualitative Methods for Health Research, Sage, London, UK, 2005.

[15] M. J. Dapaah and K. A. Senah, "HIV/AIDS clients, privacy and confidentiality: the case of two health facilities in the Ashanti Region of Ghana," BMC Public Health Journal, vol. 17, no. 1, article 41, 2016.

[16] S. B. Adebajo, A. O. Bamgbala, and M. A. Oyediran, "Attitudes of health care providers to persons living with HIV/AIDS in Lagos State, Nigeria," African Journal of Reproductive Health, vol. 7, no. 1, pp. 103-112, 2003.

[17] L. Quach, K. Mayer, S. T. McGarvey, M. N. Lurie, and P. Do, "Knowledge, attitudes, and practices among physicians on HIV/AIDS in Quang Ninh, Vietnam," AIDS Patient Care and STDs, vol. 19, no. 5, pp. 335-346, 2005.

[18] A. A. Peprah, "Determinants of patients' satisfaction at Sunyani Regional Hospital, Ghana," International Journal of Business and Social Research, vol. 4, no. 1, pp. 96-106, 2014.

[19] H. Brown, "If we sympathise with them they'll relax': fear/respect and medical care in a Kenyan hospital," Medische Antropologie, vol. 22, no. 1, pp. 125-142, 2010.

[20] S. Van Der Geest and S. Sarkodie, "The fake patient: a research experiment in a Ghanaian hospital," Social Science and Medicine, vol. 47, no. 9, pp. 1373-1381, 1998.

[21] S. Russell, "Demand-side factors affecting health seeking behaviour in Ghana," GU Journal of Health Services, vol. 5, no. 1, pp. 1-14, 2008.

[22] A. E. Armstrong, "Towards a strong virtue ethics for nursing practice," Nursing Philosophy, vol. 7, no. 3, pp. 110-124, 2006.

[23] J. H. Turner and J. E. Stets, "Sociological theories of human emotions," Annual Review of Sociology, vol. 32, pp. 25-52, 2006.

[24] USAID, Evaluation of Knowledge, Attitudes, and Practices of Health Care Providers toward HIV-Positive Patients in Tanzania, USAID, 2007.

[25] Horizons Program, "HIV and AIDS-related stigma and discrimination in Indian hospitals," Horizons Report, Population Council, Washington, DC, USA, 2006.

[26] P. Crentsil, Death, ancestors, and HIV/AIDS among the Akan of Ghana [Ph.D. dissertation], University of Helsinki, Helsinki, Finland, 2007.
[27] M. Radstake, Secrecy and Ambiguity: Home Care for People Living with HIV/AIDS in Ghana, African Studies Centre, Leiden, The Netherlands, 2003.

[28] J. M. Janzen, “Therapy management: concept, reality, process," Medical Anthropology Quarterly, vol. 1, no. 1, pp. 68-84, 1987.

[29] R. Bossart, "In the city, everybody only cares for himself': social relations and illness in Abidjan, Côte d'Ivoire," Anthropology and Medicine, vol. 10, no. 3, pp. 343-359, 2003.

[30] S. Gruskin, S. Ahmed, and L. Ferguson, "Provider-initiated HIV testing and counseling in health facilities-what does this mean for the health and human rights of pregnant women?" Developing World Bioethics, vol. 8, no. 1, pp. 23-32, 2008.

[31] A. B. Mulemi, Coping with cancer and adversity: hospital ethnography in Kenya [Ph.D. dissertation], University of Amsterdam, Amsterdam, The Netherlands; African Studies Centre, Leiden, The Netherlands, 2010.

[32] R. A. Lyimo, S. E. Stutterheim, H. J. Hospers, T. De Glee, A. Van Der Ven, and M. De Bruin, "Stigma, disclosure, coping, and medication adherence among people living with HIV/AIDS in northern Tanzania," AIDS Patient Care and STDs, vol. 28, no. 2, pp. 98-105, 2014.

[33] C. Campbell, M. Skovdal, and A. Gibbs, "Creating social spaces to tackle AIDS-related stigma: reviewing the role of church groups in sub-saharan Africa," AIDS and Behavior, vol. 15, no. 6, pp. 1204-1219, 2011.

[34] T. E. Hill, "How clinicians make (or avoid) moral judgments of patients: implications of the evidence for relationships and research," Philosophy, Ethics, and Humanities in Medicine, vol. 5, article no. 11, 2010.

[35] C. Varcoe, P. Rodney, and J. McCormick, "Health care relationships in context: an analysis of three ethnographies," Qualitative Health Research, vol. 13, no. 7, pp. 957-973, 2003.

[36] I. Shaw, "Doctors, 'dirty work' patients, and 'revolving doors,"' Qualitative Health Research, vol. 14, no. 8, pp. 1032-1045, 2004.

[37] S. V. Duh, Saving Africa from HIV/AIDS: We Can Do It, Afram Publications Ghana Limited, Accra, Ghana, 2008.

[38] J. A. Hall, T. G. Horgan, T. S. Stein, and D. L. Roter, "Liking in the physician-patient relationship," Patient Education and Counseling, vol. 48, no. 1, pp. 69-77, 2002. 


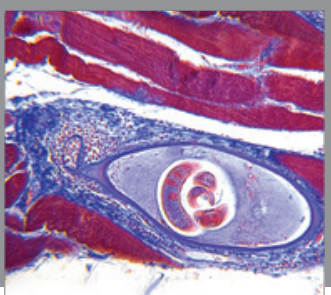

Gastroenterology

Research and Practice
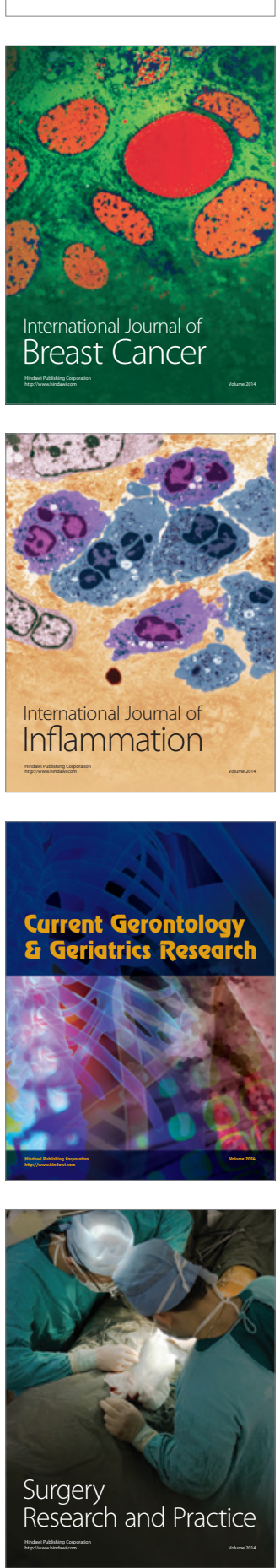

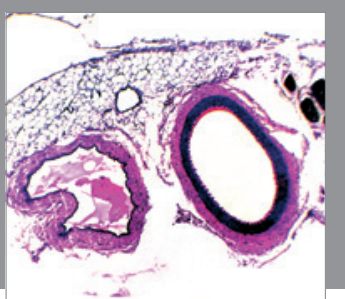

International Journal of Hypertension
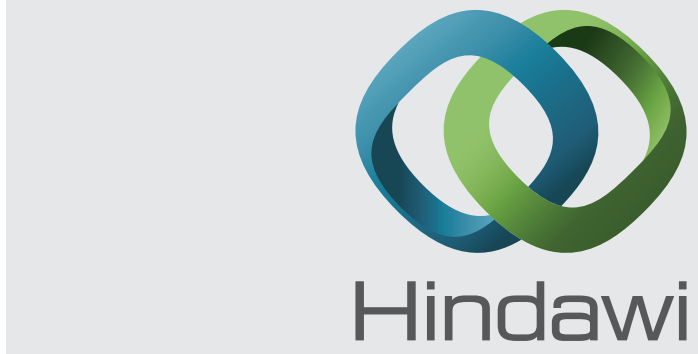

Submit your manuscripts at http://www.hindawi.com
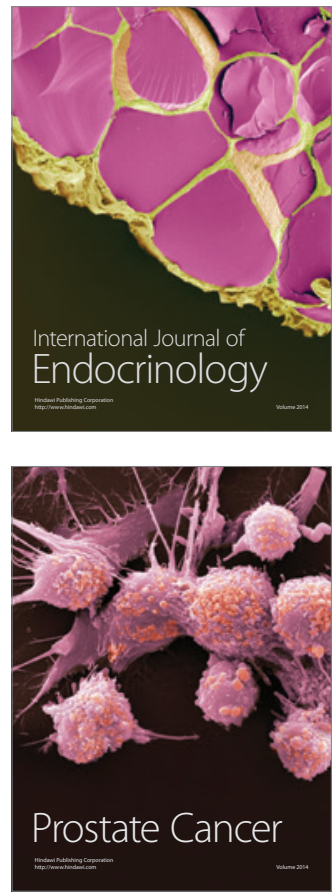

The Scientific World Journal
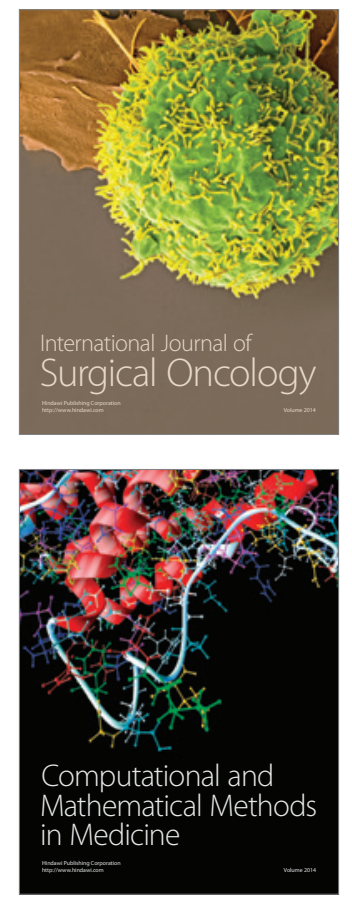
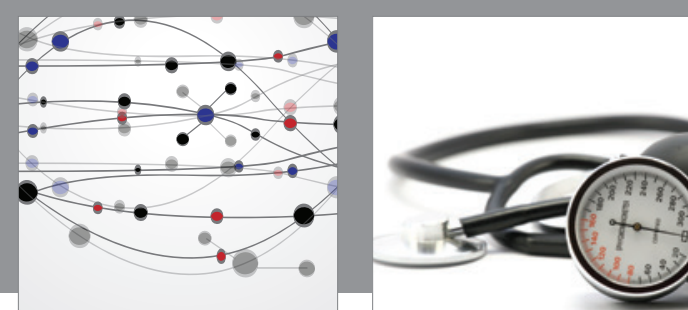

Nursing

Research and Practice

Research and Practice
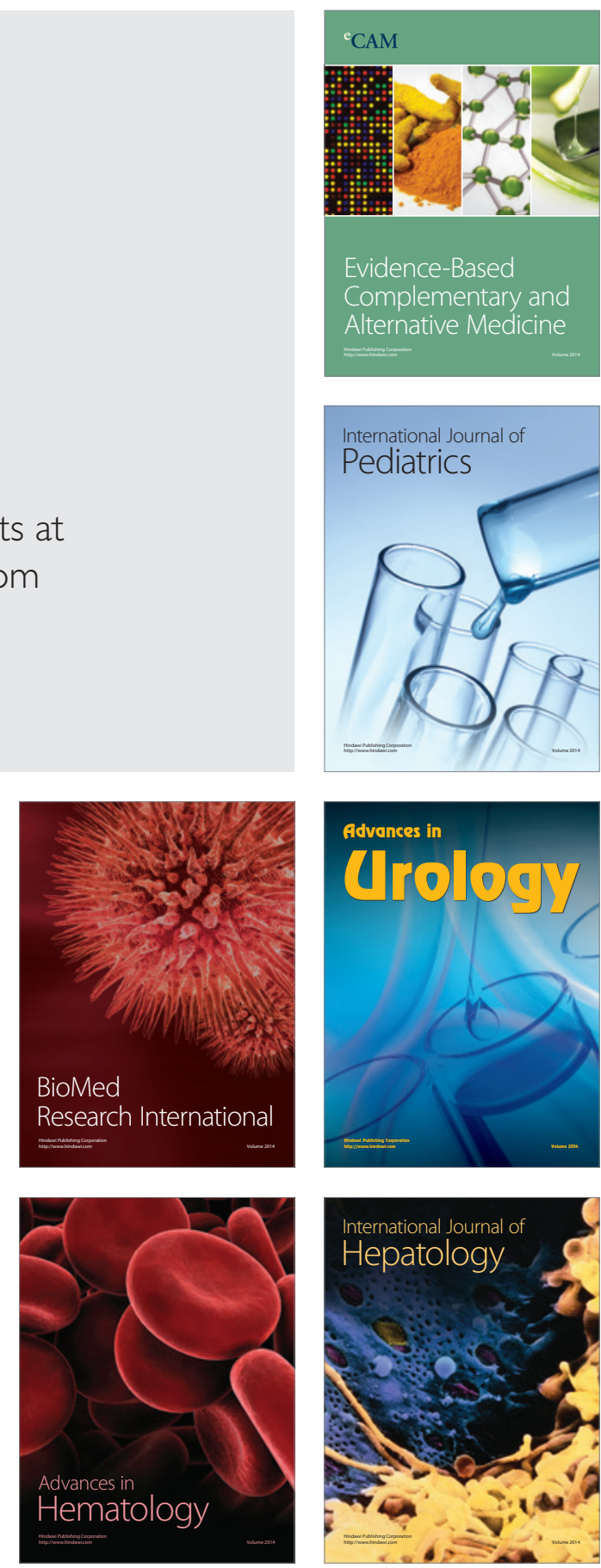
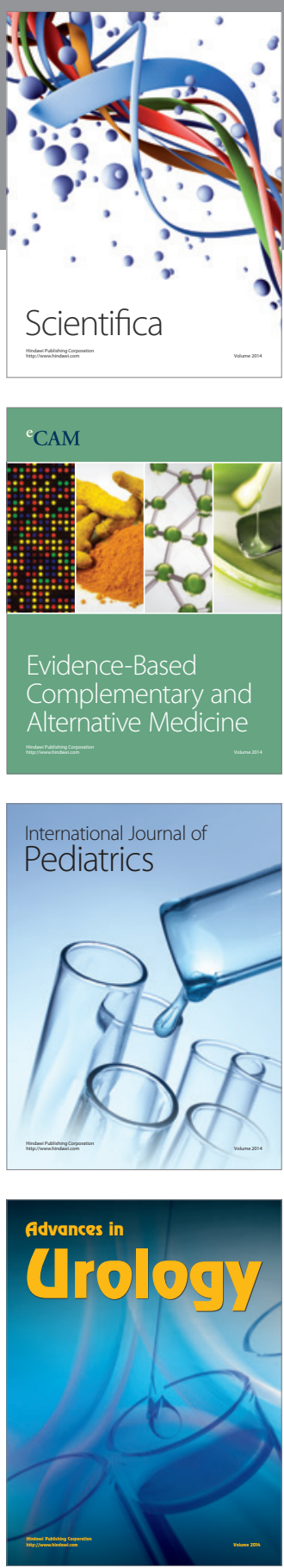

Scientifica

Evidence-Based

Complementary and

Alternative Medicine

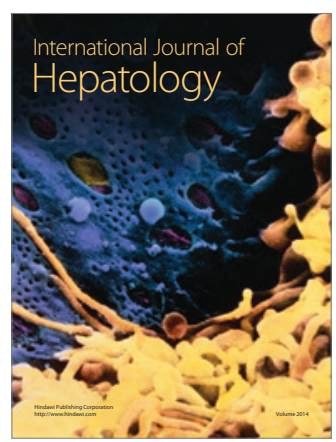

